\author{
Original
}

\title{
Nanocolumnar CdS thin films grown by glancing angle deposition from a sublimate vapor effusion source
}

\author{
Luis Germán Daza ${ }^{\mathrm{a}}$, Román Castro-Rodríguez ${ }^{\mathrm{a}}$, Marco Cirerol-Carrillo ${ }^{\mathrm{b}}$, \\ Enrique Adrián Martín-Tovar ${ }^{\mathrm{a}, *}$, José Méndez-Gamboa ${ }^{\mathrm{b}}$, Rubén Medina-Esquivel ${ }^{\mathrm{b}}$, \\ Ignacio Pérez-Quintana ${ }^{\mathrm{b}}$, Augusto Iribarren ${ }^{\mathrm{a}, \mathrm{c}}$ \\ a Department of Applied Physics, CINVESTAV-IPN, Unidad Mérida, 97310 Mérida, Yucatán, Mexico \\ ${ }^{\mathrm{b}}$ Yucatan Autonomous University, Faculty of Engineering, AP 150 Cordemex, 97310 Mérida, Yucatán, Mexico \\ c Instituto de Ciencia y Tecnología de Materiales, Universidad de La Habana, Zapata y G, Vedado, La Habana 10400, Cuba \\ Received 27 October 2016; accepted 10 February 2017 \\ Available online 9 June 2017
}

\begin{abstract}
The glancing angle deposition (GLAD) technique was used to grow cadmium sulfide (CdS) thin films on glass and indium tin oxide (ITO)-coated glass substrates from a sublimate vapor effusion source. The samples were prepared under different incident deposition flux angles $(\alpha)$ of $0^{\circ}, 20^{\circ}$ and $80^{\circ}$, while both the substrate and the source were under rotation. The temperature of the source was $923.15 \mathrm{~K}$. Scanning electron microscopy images showed that the GLAD method combined with the source produced dense nanocolumnar structures with height and diameters of $\sim 200$ and $\sim 30 \mathrm{~nm}$, respectively. The deposited films displayed a hexagonal structure with preferential (002) plane orientation and crystallites sizes between $\sim 25 \mathrm{~nm}$ and $\sim 35 \mathrm{~nm}$. A maximum solar weighted transmission of $\sim 92 \%$ was obtained for the sample prepared at $\alpha=80^{\circ}$, with a substrate/source rotation velocity ratio of 55/20 in the wavelength region of $400-900 \mathrm{~nm}$. The average band-gap energy of the films was $\sim 2.42 \mathrm{eV}$. Refractive indexes between $\sim 1.4$ and $\sim 2.4$ at a $550 \mathrm{~nm}$ the wavelength was also obtained.

(C) 2017 Universidad Nacional Autónoma de México, Centro de Ciencias Aplicadas y Desarrollo Tecnológico. This is an open access article under the CC BY-NC-ND license (http://creativecommons.org/licenses/by-nc-nd/4.0/).
\end{abstract}

Keywords: Glancing angle deposition; Cadmium sulfide; Nanostructures; Thin film; Structural properties; Columnar structure

\section{Introduction}

Cadmium sulfide (CdS) is a II-VI semiconductor material with an optical band gap of $2.42 \mathrm{eV}$ and a great diversity of applications, such as window layers for both CdTe and $\mathrm{CuInGaSe}_{2}$ (CIGS)-based solar cells devices (Elbar, Tobbeche, \& Merazga, 2015; Gerthoffer et al., 2015; Han et al., 2014; Lee et al., 2015; Li, \& Liu, 2015; Mohamed, 2015; Yun, Cha, Ahn, Kwon, \& Al-Ammar, 2014). The CdS/CdTe and CdS/CIGS heterojunction has been actively investigated as a photovoltaic junction, moreover, the $\mathrm{CdS}$ which acts as a window layer in the aforementioned solar cells has been deposited by many techniques such as sputtering (Kim, Kim, Choi, Park, \& Lee, 2015), close

\footnotetext{
* Corresponding author.

E-mail address: enrique.martin.tovar@gmail.com (E.A. Martín-Tovar).

Peer Review under the responsibility of Universidad Nacional Autónoma de México.
}

space sublimation (CSS) (Cruz et al., 2013), chemical bath deposition (Yücel \& Kahraman, 2015; Lisco et al., 2015), spray pyrolysis (Yilmaz, 2015), sol-gel, spin coating (Zhang, Huo, Li, Li, \& Yang, 2013), thermal evaporation (Baghchesara, Yousefi, Cheraghizade, Jamali-Sheini, \& Saáedi, 2016), ion beam sputtering (Liang et al., 2013) and many others. The CSS technique consists in a source of an evaporating material and a substrate which are separated by small distance in a controlled atmosphere. It has the advantage of being an inexpensive deposition method because of its simple configuration and cheap materials (Cruz-Campa \& Zubia, 2009), and it also has a high deposition rate (Alamri, 2003).

Glancing angle deposition is a novel and useful technique to grow nanostructured materials at low cost, which consists in tilting the substrate against the vapor flux. It is based on the oblique angle deposition (OAD) technique. In OAD the incident vapor flux arrives at non-normal angles (i.e., oblique angles) to a static substrate; therefore, the vapor flux can be 
treated as a vector, which has two components, a vertical and lateral component with respect to the substrate, which produces a distinct and directional columnar growth because of atomic shadowing mechanisms occurring at the substrate's surface. At the initial stage of the deposition, adatoms condense onto the substrate creating individual separated islands of deposited material, or nuclei (Kaiser, 2002). Tilting the substrate causes the incident vapor to arrive at oblique angles, which results in the appearing of shadowed regions where the vapor flux cannot directly reach the substrate. The nuclei capture the vapor flux that would have landed in the aforementioned shadowed regions, leading to the formation of a columnar growth in the same direction as the vapor source, resulting in the creation of a nano-array pattern. The glad technique differs with respect from the OAD in that the substrate is no longer static; instead, it is azimuthally rotated by a stepper motor. Controlling the rotation of the substrate and other deposition parameters, namely vapor flux incident angle, substrate temperature among others, it is possible to obtain three-dimensional nanostructures such as nano columns, zigzag, nanohelix, nanosprings and many others (Barranco, Borras, Gonzalez-Elipe, \& Palmero, 2016; Jie, Yu, Qin \& Zhengjun, 2008; Messier et al., 1997; Robbie \& Brett, 1997; Zhou, Li, Ni \& Zhang, 2011). The aforementioned nanostructures enhance the contact area for certain materials, which in turn changes their optical and structural properties; this could be beneficial for certain applications such as optoelectronic and photocatalytic devices (Jie et al., 2008;
Zhou et al., 2012). Furthermore, these structures could be integrated into a solar cell, which makes them very attractive for a wide variety of applications (Leem \& Yu, 2011; Zhou et al., 2012).

In this paper, CdS thin films were prepared using the GLAD technique along with a sublimate vapor effusion source, which was under an azimuthal counter-rotation with respect to the substrate rotation direction, the effects of this deposition method on the morphological, structural and optical properties of the films is reported.

\section{Experimental details}

Figure 1 shows the schematic representation of the evaporation source and the glass substrate in GLAD technique. $\Omega$ and $\omega$ are used to name the rotation velocity of the source and the substrate, respectively. The evaporation source consists of a graphite container axially rotated at $\Omega=20 \mathrm{rpm}$ and heated between two halogen lamps at $923 \mathrm{~K} .2 \mathrm{~g}$ of a CdS powder ( $99.99 \%$ pure) were placed in the container. The pressure within the cavity was close to $\sim 7 \times 10^{5} \mathrm{~Pa}$. This was calculated assuming and ideal gas behavior $\left(P V=n k_{B} T\right)$, where $V=14.73 \mathrm{~cm}^{3}$ is the volume of the container, $T(923 \mathrm{~K})$ the evaporation temperature of the source, $k_{B}$ is the Boltzmann's constant and $n$ the numbers of moles. It must be clarified that although the ideal gas model might not be totally accurate to model the pressure of the container, it was made as a first approximation for the sake of simplicity, and

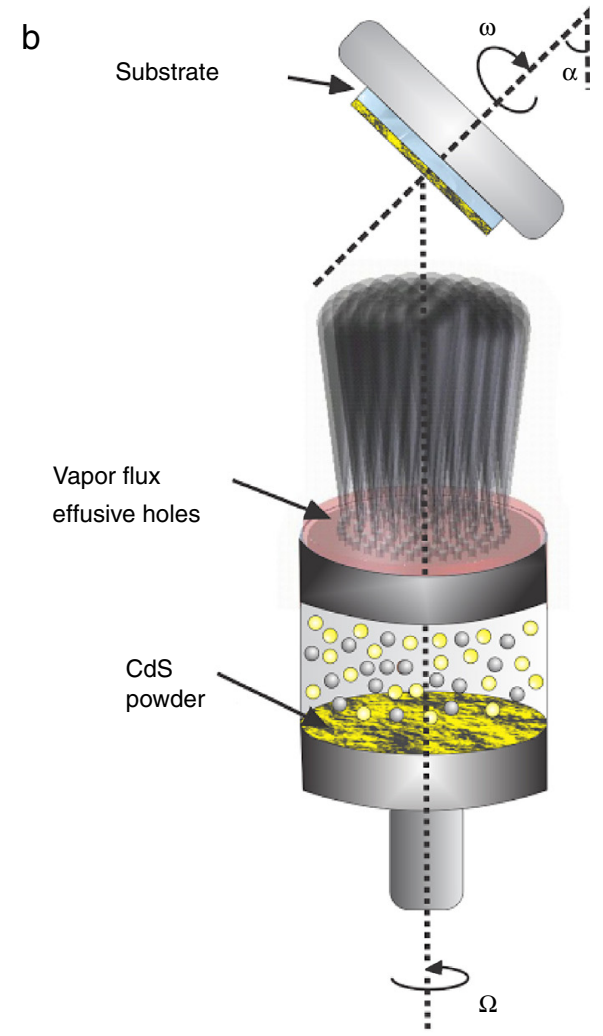

Fig. 1. Experimental setup for GLAD method combined with the sublimate vapor effusion source. The left side (a) shows the GLAD apparatus as it is implemented in the effusion source. Substrate and source movements are accomplished by two independent motors. On the bottom right (b), the source container is shown. 
for the immediate intents and purposes of this work it is considered sufficiently correct. The container has a top cover with 20 holes of $\sim 1.5 \mathrm{~mm}$ diameter symmetrically distributed as is shown in Figure 1(b); these holes have a vapor effusion function. The vapor flux density $(\phi)$ for each hole was estimated using the cosine of Knudsen law (Herman \& Sitter, 2012):

$\phi=3.153 \times 10^{22} \cdot \frac{a^{2}}{\pi L}\left(\frac{\rho G}{\sqrt{T M}}\right) \cos \alpha$

where $a=1.77 \times 10^{-2} \mathrm{~cm}^{2}$ is the area of a single hole, $L=6.0 \mathrm{~cm}$ is the distance between the substrate and the evaporation source, $P_{G}$ is the CdS vapor partial pressure within the container, $T$ $(923 \mathrm{~K})$ is the evaporation temperature of the source, $M$ is the $\mathrm{CdS}$ molecular weight and $\alpha$ is the incident deposition flux angle. The flux density has an angular distribution in each hole; this produces a confined region of $\mathrm{CdS}$ vapor distributed between the substrate and the evaporation source.

To grow vertical nanocolumnar structures of $\mathrm{CdS}$ thin films, the substrate was put in GLAD mode, as shown in Figure 1(b), and heated by radiation using two halogen lamps as depicted in Figure 1(a). The substrate was azimuthally rotated using angular velocities with values $\omega=20,30,40,55$, $150,350,700$ and $1020 \mathrm{rpm}$, and tilted using $\alpha=0^{\circ}, 20^{\circ}$ and $80^{\circ}$, as shown in Figure 1(b). The experimental set-up procedure was as follows: Corning 2947 glasses and commercial ITO/Glass (Delta Technologies CB-40IN-0107) with dimensions of $25 \mathrm{~mm} \times 25 \mathrm{~mm} \times 0.7 \mathrm{~mm}$ were used as substrates, which were sequentially cleaned prior to the deposition by an ultrasonic agitation bath in distilled water, acetone and isopropyl alcohol for $5.0 \mathrm{~min}$ each. Subsequently, they were dried with $\mathrm{N}_{2}$ and heated at a substrate temperature $\left(T_{S}\right)$ of $623 \mathrm{~K}$. After reaching $T_{S}$, a shutter placed above the evaporation source was removed, the substrate was put in front of it and adjusted in GLAD mode with a separation distance of $L=6.0 \mathrm{~cm}$. The source and the substrate were put in counter-rotation; this means that the source rotated in a direction opposite to that of the substrate. The background pressure in the vacuum chamber was $\sim 4 \mathrm{~Pa}$ and the deposition time was 1.0-3.0 min for different types of samples.

The cross-sectional morphologies of CdS films were characterized using a field emission scanning electron microscope (FESEM) JEOL 7600F instrument. The X-ray diffraction (XRD) data was obtained by a D5000Siemens X-ray diffractometer with a beam under of $\mathrm{CuK} \alpha$ filtered monochromatic radiation $(\lambda=0.15418 \mathrm{~nm})$ by $40 \mathrm{kV}$ with $35 \mathrm{~mA}$ and aperture diaphragm of $0.2 \mathrm{~mm}$. The diffractograms were registered in the step scan mode with a beam incidence angle of $1^{\circ}$ and recorded in $2 \theta=0.02^{\circ}$ steps with a step time of $10 \mathrm{~s}$ in a $2 \theta$ range of $20-55^{\circ}$. The optical measurements were carried out using a UV-vis Agilent 8453 spectrophotometer with $0.1 \mathrm{~nm}$ resolution, in the range of $400-900 \mathrm{~nm}$. The optical band gaps were calculated with direct transitions only.

\section{Results and discussion}

The flux density value defined by Eq. (1) decreases as $\alpha$ increases. Particularly, for $\alpha=80^{\circ}, \phi$ was estimated to be $\sim 1 \times 10^{21} \mathrm{CdS}$ atoms $/ \mathrm{cm}^{2} \mathrm{~s}$. At first glance, the films showed no evidence of pin-hole formation; this could be explained by the counter-rotation between the substrate and the evaporation source, which in turn could favor a uniform angular distribution of the CdS vapor flux.

The optimal ratio of $\omega / \Omega$ was found to be $55 / 20$, this value was selected from the optimization of the solar weighted transmission (SWT) calculation, while the other deposition parameters remained constant, this will be discussed in more detail later in the text.

After the growth of the CdS thin films, the transversal morphology was observed by FESEM with a magnification of $50,000 \times$ and $100,000 \times$. In order to obtain a SEM image with good quality, which would allow the correct visualization of the nanocolumnar structures, it was necessary to employ a deposition time of 3 and $2 \mathrm{~min}$ for the glass and ITO/glass substrate, respectively.

The cross-sectional image of the CdS arrays on glass substrates grown at $\alpha=80^{\circ}$ is shown in Figure 2(a). Highly uniform and densely packed arrays of CdS nanocolumnar structures were successfully formed; they displayed vertical alignments with great uniformity through all their thicknesses, which was of $\sim 300 \mathrm{~nm}$. The diameter of these structures was approximately $30 \mathrm{~nm}$, and it was estimated from the zoom on the FESEM crosssection images. The presence of fissures with small gaps which divide some of these structures can also be observed.

Figure 2(b) shows a transversal structure for the sample grown glass/ITO substrate at $\alpha=80^{\circ}$. A uniform and dense columnar distribution was also observed, and the thickness of the thin film was approximately of $\sim 200 \mathrm{~nm}$. However, the presence of fissures was less in comparison to the sample shown in Figure 2(a), since they were not present through all the thickness of the film. This was evidence that the $\mathrm{CdS}$ deposition was more densely packed on the glass/ITO substrate.

Figure 3 shows the XRD normalized pattern for the thin films grown at $\alpha=0^{\circ}, 20^{\circ}$ and $80^{\circ}$ with $1.0 \mathrm{~min}$ of deposition time. The single-phase hexagonal CdS Wurtzite structure (Razik, 1987) is observed with a preferential orientation in the (002) plane. Low intensity peaks for the (100), (101), (110), (103) and (112) planes are also observed. The XRD data showed that all the peaks are shifted toward higher $2 \theta$ values in comparison to that of the standard pattern $\left(2 \theta=26.507^{\circ}\right)$; this is evidence of compressive strain (Zak, Majid, Abrishami, \& Yousefi, 2011). The crystallite size $\left(D_{X R D}\right)$ was calculated from the plane (002) using the Scherrer's equation (Wang et al., 2015):

$D_{X R D}=\frac{0.9 \lambda}{\beta_{002} \cos \theta_{002}}$

where $\beta_{002}$ is the full-width at half-maximum and $\lambda$ is the wavelength of the X-ray radiation employed $(\lambda=0.15418 \mathrm{~nm})$. The values of $D_{X R D}$ are given in Table 1 . The crystallite sizes values were between $\sim 25 \mathrm{~nm}$ and $\sim 35 \mathrm{~nm}$. The lattice parameter $c_{002}$ was calculated employing the standard lattice geometry 

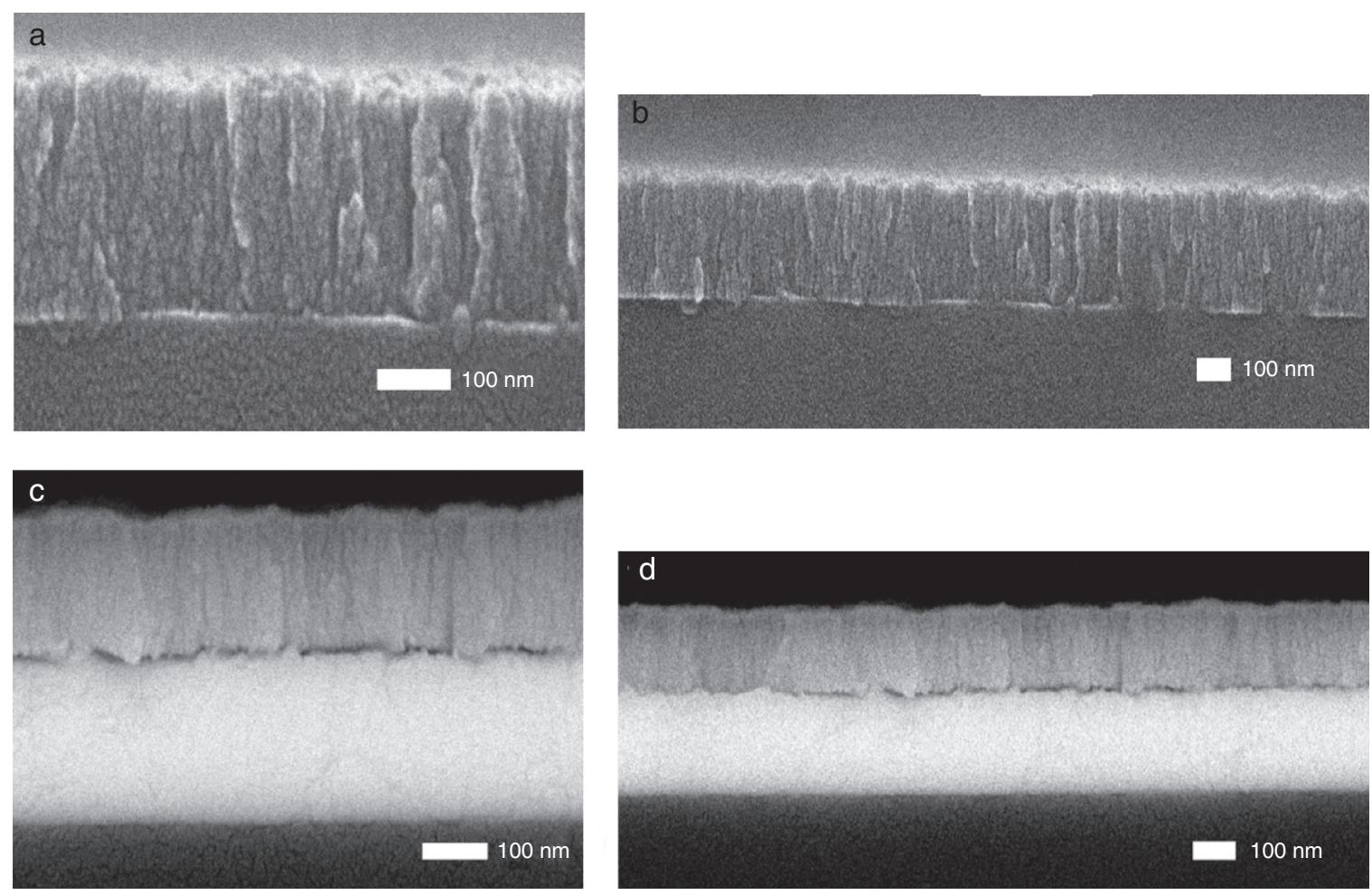

Fig. 2. FESEM image of: vertical nano columnar CdS as nanostructure grown at $\alpha=80^{\circ}$ on a glass substrate with a magnification of (a) $100,000 \times$ and (b) $50,000 \times$. Vertical nano columnar CdS as nanostructure layer grown at $\alpha=80^{\circ}$ on an indium tin oxide (ITO)-coated glass substrate with (c) $100,000 \times$ and (d) $50,000 \times$.

Table 1

Structural parameters for samples with different incident deposition flux angles.

\begin{tabular}{|c|c|c|c|c|c|}
\hline$\alpha$ (degree) & $2 \theta_{002}$ (degree) & $\beta_{002}$ (radians) $\times 10^{-3}$ & $c_{002}(\mathrm{~nm})$ & $\varepsilon(\%)$ & $D_{X R D}(\mathrm{~nm})$ \\
\hline 0 & 26.54 & 4.6 & 0.6711 & -0.119 & $\sim 31$ \\
\hline 20 & 26.57 & 4.1 & 0.6705 & -0.208 & $\sim 35$ \\
\hline 80 & 26.63 & 5.7 & 0.6691 & -1.61 & $\sim 25$ \\
\hline
\end{tabular}

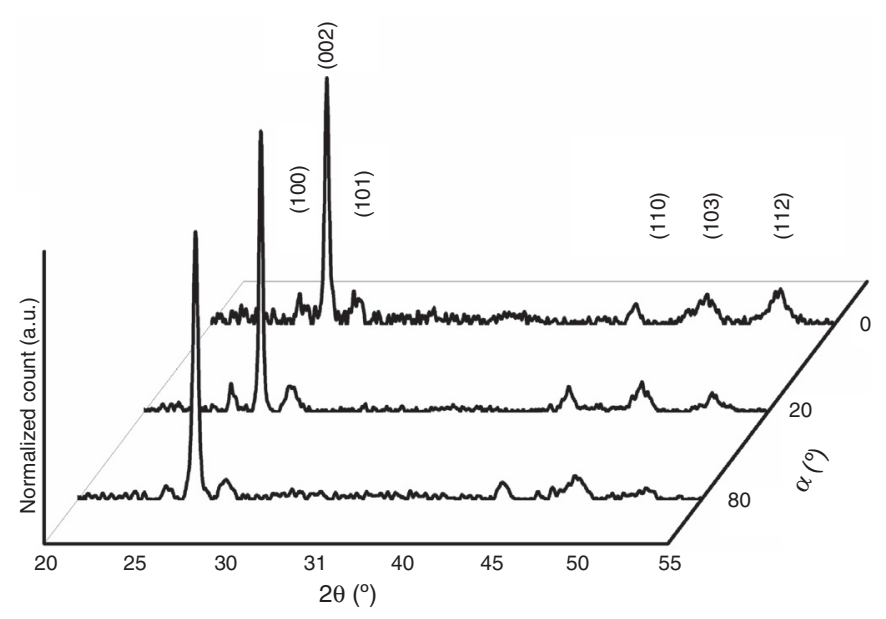

Fig. 3. XRD normalized pattern for CdS thin film grown with different incident deposition flux angles.

equations for the hexagonal structure (Iribarren, HernándezRodríguez, \& Maqueira, 2014; Kaur, Kumar, Sathiaraj, \& Thangaraj, 2013). As it was mentioned before, the shifting of the $2 \theta$ positions to higher values with respect to the CdS standard pattern is evidence of a negative compressive strain, this suggests that the lattice parameters of the unit cell would show a decrease, this agrees with the reported $c_{002}$ lattice parameter values summarized in Table 1, which are in general smaller than those of the standard CdS $\left(c_{0}=0.6719 \mathrm{~nm}\right)$.

The $c_{002}$ parameter decreases for higher incident deposition flux angles, this correlation between the aforementioned parameters is illustrated in Figure 4. The general reduction of the $c_{002}$ values indicates that there is shrinkage on the $c$-axis for the $\mathrm{CdS}$ unit cell with respect to the pattern value. Furthermore, the strain $\varepsilon$ along the $c$-axis was calculated by using the expression $\varepsilon=\left(c-c_{0}\right) / c_{0} \times 100 \%$ (Ghosh, Basak, \& Fujihara, 2004). The absolute values of the $c$-axis strain increase as $\alpha$ increases, this is also shown in Table 1 . The negative values of $\varepsilon$ confirm shrinkage in the $c$-axis. This suggests that a high incident deposition flux angle leads to a lattice compression effect along the $c$-axis direction, as it was also stated in the XRD analysis.

In order to find the optimal $\omega / \Omega$ ratio the solar weighted transmission (SWT) was calculated for the thin films grown at different substrate rotation speeds $(\omega)$. Figure 5 shows the SWT as a function $\omega$, for different samples all grown at $\alpha=80^{\circ}$ and with 1.0 min of deposition time. Based on the SEM images, 


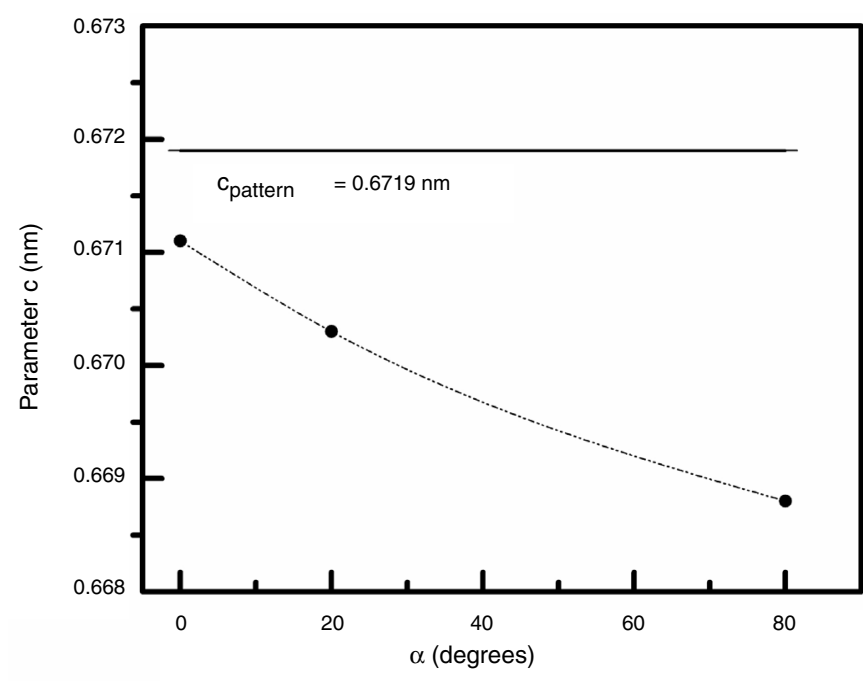

Fig. 4. $c_{002}$ parameter versus the tilting angle of the substrate.

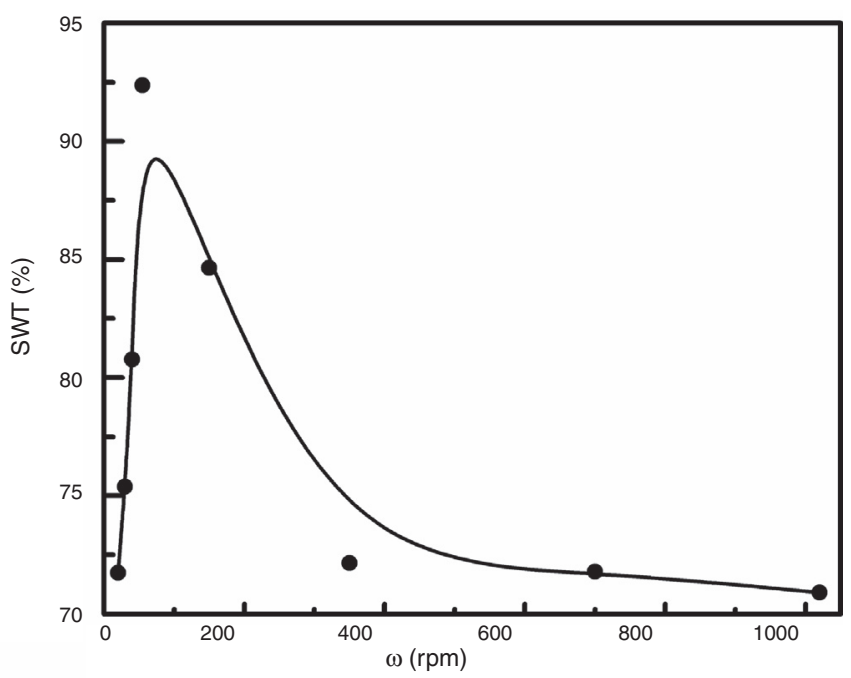

Fig. 5. Solar weighted transmission (SWT) measurements of CdS thin films as a function of substrate rotation grown with deposition flux angle of $\alpha=80^{\circ}$.

this value of $\alpha$ was selected since it allowed observing with more clarity the nano-columnar deposition on the substrate. The SWT formula is given by Mendez-Gamboa, Castro-Rodriguez, Perez-Quintana, Medina-Esquivel, and Martel-Arbelo (2016):

$S W T=\frac{\int_{\lambda_{1}}^{\lambda_{2}} T(\lambda) S(\lambda) d \lambda}{\int_{\lambda_{1}}^{\lambda_{2}} S(\lambda) d \lambda}$

where $S(\lambda)$ is the AM 1.5 solar radiation spectrum, $T(\lambda)$ is the optical transmittance, and the numerator of Eq. (3) represents the solar photon flux-weighted transmittance for the sample. The SWT is the ratio of the usable photons transmitted from the total available photons, it can be estimated through the normalization of the transmittance spectra, and this was done by integrating the solar spectral photon flux over the wavelength range of $400-900 \mathrm{~nm}$. Figure 5 shows that SWT reached a maximum of $\sim 92 \%$ at $\omega=55 \mathrm{rpm}$, and for greater $\omega$ it decreased to

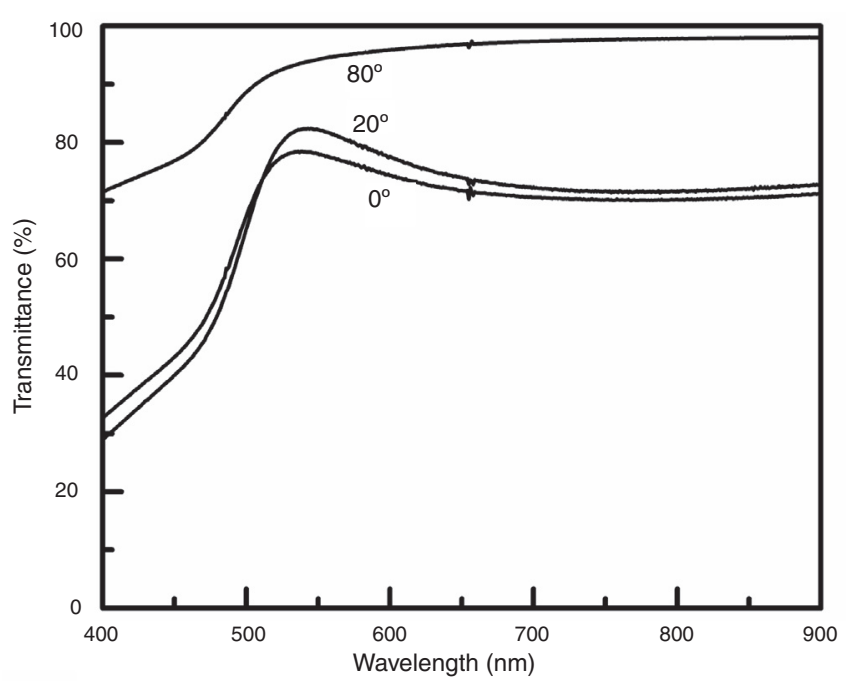

Fig. 6. Transmittance spectra of CdS thin films grown with incident deposition flux angles.

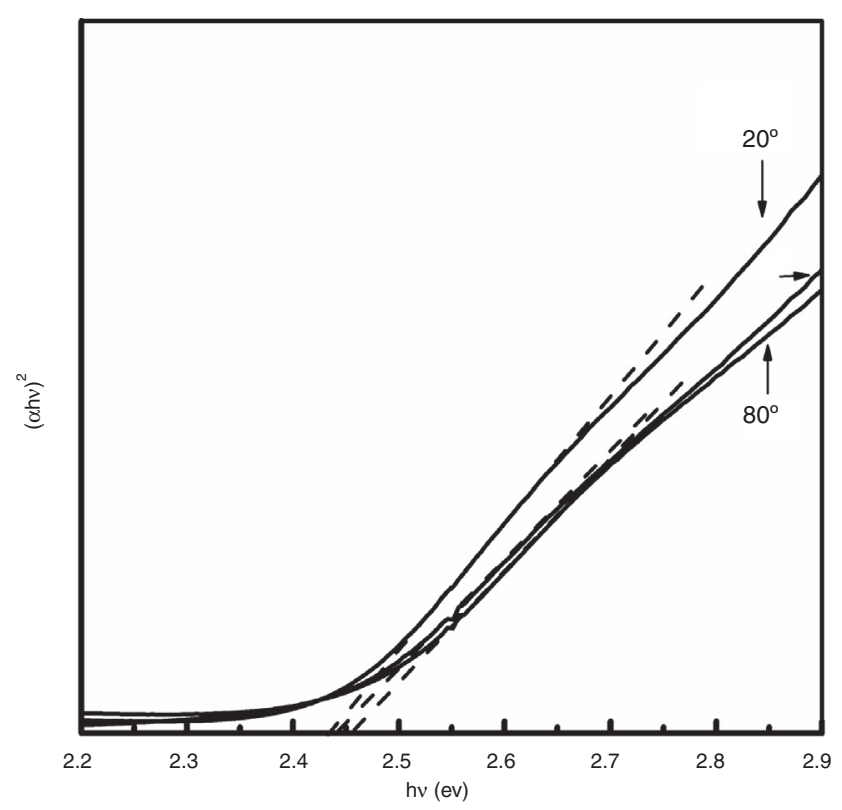

Fig. 7. Tauc plot of CdS thin films growth at $\alpha=0^{\circ}, 20^{\circ}$ and $80^{\circ}$.

$\sim 71 \%$. In accordance with the calculations of SWT a ratio of $\omega / \Omega=55 / 20$ was selected as the optimum value.

Figure 6 shows the transmittance spectrum of samples grown at $\alpha=0^{\circ}, 20^{\circ}$ and $80^{\circ}$ with $1.0 \mathrm{~min}$ deposition time. A transmittance value of $\sim 95 \%$ was observed for the sample with $\alpha=80^{\circ}$. The increasing in the transmittance value is due to the change in the thickness, since a larger tilting angle leads to a smaller deposition rate (Nagiri, Yambem, Lin, Burn, \& Meredith, 2015), resulting in thinner samples, which in turn will produce higher transmittance values. As can be seen, the transmittance for the film grown at $\alpha=80^{\circ}$ at the $400 \mathrm{~nm}$ wavelength is less than $80 \%$, while it is below $40 \%$ for the samples with $\alpha=0^{\circ}$ and $20^{\circ}$. The optical band-gap energy $\left(E_{G}\right)$ was calculated using the Tauc formalism (Tauc, Grigorovici, Vancu, 1966) as shown in Figure $7, E_{G}$ values between $\sim 2.43 \mathrm{eV}$ and $\sim 2.45 \mathrm{eV}$ were 


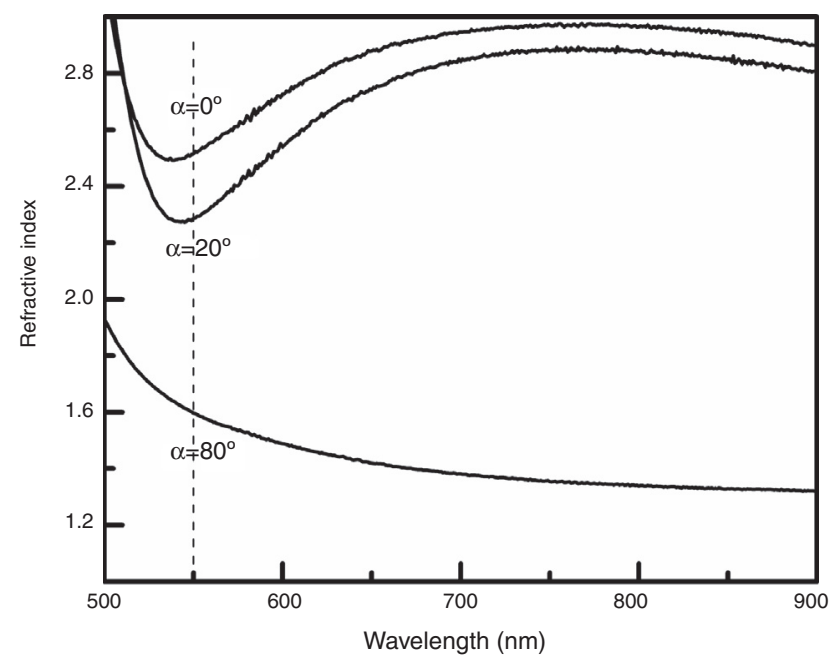

Fig. 8. Refractive index versus wavelength of thin films grown at different values of $\alpha$ for a $500-900 \mathrm{~nm}$ wavelength range.

obtained, which agrees very well with the previous reports of the band gap energy for the CdS (Mohamed, 2015). Additionally, the refractive index $(n)$ was calculated from the equation (Kim, Yim, Son, \& Leem, 2012):

$n=\frac{1+R}{1-R}+\sqrt{\frac{4 R}{(1-R)^{2}}-K^{2}}$

where $R$ is the normal-incident light reflection, $k$ is the extinction coefficient defined as $k=\alpha_{a b s} \lambda / 4 \pi$, where $\alpha_{a b s}$ is the absorption coefficient and $\lambda$ the wavelength. In the region below the band gap energy the absorption follows $A \rightarrow 0$.Then the expression $T+R+A=1$ can be reduced to $R=1-T$ from where it is possible to estimate the reflected light. The calculated refractive index at different incident deposition flux angles are depicted in Figure 8, which shows that it decreases as $\alpha$ increases. For $\alpha=80^{\circ}$ the refractive index was $\sim 1.6$ at wavelength near $550 \mathrm{~nm}$, for $\alpha=0^{\circ}$ and $20^{\circ}$ it was $\sim 2.4$, which is very close to the refractive index value that is required for a thin film that is desired to be used as an antireflection layer between ITO and CdTe according to the law $\left(n_{I T O} n_{C d T e}\right)^{1 / 2}$ (Prevo, Hwang, \& Velev, 2005) where $n_{\text {ITO }}$ and $n_{C d T e}$ are the refractive index of ITO and CdTe layers, respectively.

\section{Conclusions}

In this paper, an innovative source for vapor effusion is reported. Such a source was employed to provide a vapor flux in the GLAD deposition mode which led to the obtaining of $\mathrm{CdS}$ vertical nanostructured thin films. The source and the substrate were counter-rotated with respect to each other, at an optimal ratio $\omega / \Omega: 55 / 20$. The effect caused on the morphological, structural and optical properties for the CdS thin films grown at different incident deposition flux angles was investigated. The principal characteristics of these CdS nanocolumnar thin films were a uniform distribution over the substrate with dimensions of height and diameters of $\sim 200 \mathrm{~nm}$ and $\sim 30 \mathrm{~nm}$, respectively. The films showed a single hexagonal wurtzite structure phase with a preferential (002) plane orientation, band gap energy of $\sim 2.42 \mathrm{eV}$ and a refractive index between $\sim 1.4$ and $\sim 2.4$ in wavelength of $550 \mathrm{~nm}$.

\section{Conflict of interest}

The authors have no conflicts of interest to declare.

\section{Acknowledgments}

Authors wish to thank Oswaldo Gómez, Mario Herrera, Daniel Aguilar, Dora Huerta and Wilian Cauich for technical assistance and Lourdes Pinelo for her secretary assistance. This work has been supported by Project No. CB/2012/178748 CONACYT/México. One of the authors (A. Iribarren) also thanks CONACYT/México for sabbatical leaves for Mexican and foreign researchers living abroad, under program No. 260967.

\section{References}

Alamri, S. N. (2003). The growth of CdTe thin film by closes pace sublimation system. Physica Status Solidi A: Applications and Materials Science, 200(2), 352-360.

Baghchesara, M. A., Yousefi, R., Cheraghizade, M., Jamali-Sheini, F., \& Saáedi, A. (2016). Photocurrent application of Zn-doped CdS nanostructures grown by thermal evaporation method. Ceramics International, 42, 1891-1896.

Barranco, A., Borras, A., Gonzalez-Elipe, A. R., \& Palmero, A. (2016). Perspectives on oblique angle deposition of thin films: From fundamentals to devices. Progress in Materials Science, 76, 59-153.

Cruz, L. R., Pinheiro, W. A., Medeiro, R. A., Ferreira, C. L., Dhere, R. G., \& Duenow, J. N. (2013). Influence of heat treatment and back contact processing on the performance of $\mathrm{CdS} / \mathrm{CdTe}$ thin film solar cells produced in a CSS in-line system. Vacuum, 87, 45-49.

Cruz-Campa, J. L., \& Zubia, D. (2009). CdTe thin film growth model under CSS conditions. Solar Energy Materials and Solar Cells, 93, 15-18.

Elbar, M., Tobbeche, S., \& Merazga, A. (2015). Effect of top-cell CGS thickness on the performance of CGS/CIGS tandem solar cell. Solar Energy, 122, 104-112.

Gerthoffer, A., Roux, F., Emieux, F., Faucherand, P., Fournier, H., Grenet, L., et al. (2015). CIGS solar cells on flexible ultra-thin glass substrates: Characterization and bending test. Thin Solid Films, 592, 99-104.

Ghosh, R., Basak, D., \& Fujihara, S. (2004). Effect of substrate-induced strain on the structural, electrical, and optical properties of polycrystalline $\mathrm{ZnO}$ thin films. Journal of Applied Physics, 96(5), 2689-2692.

Han, J.-F., Liao, C., Cha, L.-M., Jiang, T., Xie, H. M., Zhao, K., et al. (2014). TEM and XPS studies on CdS/CIGS interfaces. Journal of Physics and Chemistry of Solids, 75(12), 1279-1283.

Herman, M., \& Sitter, H. (2012). Molecular beam epitaxy: Fundamentals and current status. Berlin, Germany: Ed. Springer Science y Business Media.

Iribarren, A., Hernández-Rodríguez, E., \& Maqueira, L. (2014). Structural, chemical and optical evaluation of $\mathrm{Cu}$-doped $\mathrm{ZnO}$ nanoparticles synthesized by an aqueous solution method. Materials Research Bulletin, 60, 376-381.

Jie, N., Yu, Z., Qin, Z., \& Zhengjun, Z. (2008). Morphology in-design deposition of $\mathrm{HfO}_{2}$ thin films. Journal of the American Ceramic Society, 91(10), $3458-3460$.

Kaiser, N. (2002). Review of the fundamentals of thin-film growth. Applied Optics, 41, 3053-3060.

Kaur, J., Kumar, P., Sathiaraj, T. S., \& Thangaraj, R. (2013). Structural, optical and fluorescence properties of wet chemically synthesized $\mathrm{ZnO}: \mathrm{Pd}^{2+}$ nanocrystals. International Nano Letters, 3(1), 4.

Kim, M. S., Yim, K. G., Son, J. S., \& Leem, J. Y. (2012). Effects of Al concentration on structural and optical properties of Al-doped $\mathrm{ZnO}$ thin films. Bulletin of the Korean Chemical Society, 33(4), 1235-1241. 
Kim, D., Kim, Y. P., Choi, Y., Park, Y. S., \& Lee, J. (2015). Optical and structural properties of sputtered CdS films for thin film solar cell applications. Material Research Bulletin, 69, 73-78.

Lee, S., Lee, E. S., Kim, T. Y., Cho, J. S., Eo, Y. J., Yun, J. H., et al. (2015). Effect of annealing treatment on CdS/CIGS thin film solar cells depending on different CdS deposition temperatures. Solar Energy Materials \& Solar Cells, 141, 299-308.

Leem, J. W., \& Yu, J. S. (2011). Glancing angle deposited ITO films for efficiency enhancement of a-Si:H/ $\mu \mathrm{c}-\mathrm{Si}: \mathrm{H}$ tandem thin film solar cells. Optics Express, $19,258-269$.

Li, H., \& Liu, X. (2015). Improved performance of CdTe solar Cells with CdS treatment. Solar Energy, 115, 603-612.

Liang, G.-X., Fana, P., Zheng, Z.-H., Luo, J.-T., Zhanga, D.-P., Chen, H.-M., et al. (2013). Room-temperature preparation and properties of cadmium sulfide thin films by ion-beam sputtering deposition. Applied Surface Science, 273, 491-495.

Lisco, F., Kaminski, P. M., Abbas, A., Bass, K., Bowers, J. W., Claudio, G., et al. (2015). The structural properties of CdS deposited by chemical bath deposition and pulsed direct current magnetron sputtering. Thin Solid Films, $582,323-327$.

Mendez-Gamboa, J. A., Castro-Rodriguez, R., Perez-Quintana, I. V., MedinaEsquivel, R. A., \& Martel-Arbelo, A. (2016). A figure of merit to evaluate transparent conductor oxides for solar cells using photonic flux density. Thin Solid Films, 599, 14-18.

Messier, R., Gehrke, T., Frankel, C., Venugopal, V. C., Otaño, W., \& Lakhtakia, A. (1997). Engineered sculptured nematic thin films. Journal of Vacuum Science \& Technology A: Vacuum, Surfaces, and Films, 15, 2148

Mohamed, H. A. (2015). Optimized conditions for the improvement of thin films CdS/CdTe solar cells. Thin Solid Films, 589, 72-78.

Nagiri, R. C. R., Yambem, S. D., Lin, Q., Burn, P. L., \& Meredith, P. (2015). Room-temperature tilted-target sputtering deposition of highly transparent and low sheet resistance $\mathrm{Al}$ doped $\mathrm{ZnO}$ electrodes. Journal of Materials Chemistry C, 3(20), 5322-5331.

Prevo, B. G., Hwang, Y., \& Velev, O. D. (2005). Convective assembly of antireflective silica coatings with controlled thickness and refractive index. Chemistry of Materials, 17(14), 3642-3651.
Razik, N. A. (1987). Use of a standard reference material for precise lattice parameter determination of materials of hexagonal crystal structure. Journal of Materials Science Letters, 6(12), 1443-1444.

Robbie, K., \& Brett, M. J. (1997). Sculptured thin films and glancing angle deposition: Growth mechanics and applications. Journal of Vacuum Science \& Technology A: Vacuum, Surfaces, and Films, 15, 1460.

Tauc, J., Grigorovici, R., \& Vancu, A. (1966). Optical properties and electronic structure of amorphous germanium. Physica Status Solidi B: Basic Solid State Physics, 15, 627-637.

Wang, L. W., Wu, F., Tian, D. X., Li, W. J., Fang, L., Kong, C. Y., et al. (2015). Effects of Na content on structural and optical properties of Na-doped $\mathrm{ZnO}$ thin films prepared by sol-gel method. Journal of Alloys and Compounds, 623, 367-373.

Yilmaz, S. (2015). The investigation of spray pyrolysis grown CdS thin films doped with fluorine atoms. Applied Surface Science, 357, 873-879.

Yücel, E., \& Kahraman, S. (2015). The effects of coumarin additive on the properties of CdS thin films grown by chemical bath deposition. Ceramics Internationals, 41, 4726-4734.

Yun, J. H., Cha, E. S., Ahn, B. T., Kwon, H., \& Al-Ammar, E. A. (2014). Performance improvement in CdTe solar cells by modifying the CdS/CdTe interface with a Cd treatment. Current Applied Physics, 14(4), 630-635.

Zak, A. K., Majid, W. A., Abrishami, M. E., \& Yousefi, R. (2011). X-ray analysis of $\mathrm{ZnO}$ nanoparticles by Williamson-Hall and size-strain plot methods. Solid State Sciences, 13(1), 251-256.

Zhang, C., Huo, H., Li, Y., Li, B., \& Yang, Y. (2013). Preparation of helical CdS nanotubes using a sol-gel transcription approach. Materials Letters, 102, $50-52$.

Zhou, Q., Li, Z., Ni, J., \& Zhang, Z. (2011). A simple model to describe the rule of glancing angle deposition. Materials Transactions, 52(3), 469-473.

Zhou, Y., Taima, T., Miyadera, T., Yamanari, T., Kitamura, M., Nakatsu, K., et al. (2012). Glancing angle deposition of copper iodide nanocrystals for efficient organic photovoltaics. Nano Letters, 12(8), 4146-4152. 